\title{
The interaction between mood and cognitive function studied with PET
}

\author{
S. C. BAKER, C. D. FRITH AND R. J. DOLAN ${ }^{1}$ \\ From the Wellcome Department of Cognitive Neurology, Institute of Neurology; MRC Cyclotron Unit, \\ Hammersmith Hospital; Royal Free Hospital School of Medicine; National Hospital for Neurology and \\ Neurology and Neurosurgery; and University College London
}

\begin{abstract}
Background. Experimentally induced depressed mood is a suggested model for retarded depression. We describe the neural response associated with induced mood and the locus of the interaction between systems mediating mood and cognitive function.

Methods. Normal subjects performed a verbal fluency task during induced elated and depressed mood states. Regional cerebral blood flow ( $\mathrm{CCBF}$ ) was measured as an index of neural activity using Positron Emission Tomography (PET).

Results. In both elated and depressed mood state rCBF was increased in lateral orbitofrontal cortex, $\mathrm{rCBF}$ was also increased in the midbrain in elated mood. In the depressed condition $\mathrm{rCBF}$ was decreased in rostral medial prefrontal cortex. Verbal fluency produced an expected increase of $\mathrm{rCBF}$ in left dorsolateral prefrontal, inferior frontal and premotor cortex, anterior cingulate and insula cortex bilaterally, the left supramarginal gyrus posteriorly and the thalamus. Activation in the verbal fluency task was attenuated throughout the left prefrontal, premotor and cingulate cortex and thalamus in both elated and depressed mood conditions. An attenuation of anterior cingulate activation was specific to depressed mood.

Conclusions. Alteration of mood is associated with activation of orbitofrontal cortex which may be critical to the experience of emotion. The mood induced modulation of verbal fluency induced activations is consistent with resting state findings of decreased function in these regions in depressed patients. The present data suggest that resting state $\mathrm{rCBF}$ profile may represent the modulation of spontaneous activity in this network by a core system that is dysfunctional in depression.
\end{abstract}

\section{INTRODUCTION}

Depressed mood and lack of emotional reactivity is pathognomic of depression. Cognitive and motivational abnormalities are also integral to depressive disorders (Weingartner et al. 1981). Functional imaging studies have revealed distinct patterns of abnormal resting regional cerebral blood flow (rCBF) in depression that correlate with the principal symptom profiles (Dolan et al. 1992; Bench et al. 1993).

\footnotetext{
1 Address for correspondence: Professor R. J. Dolan, Wellcome Department of Cognitive Neurology, Institute of Neurology, 12 Queen Square, London WC1 3BG.
}

Cognitive techniques have been widely used to alter mood in normal subjects (GerrardsHesse et al. 1994). The distinction between normal and pathological mood states has been emphasized by psychiatrists. However, a mood state characterized by negative self-evaluation and psychomotor changes analogous to those associated with clinical depression can be induced in normal subjects (Velten, 1968) and is referred to as 'depressed mood' in contrast to normal sadness. Psychologically induced depressed mood is also regarded as a valid model of retarded depression (Clarke, 1983; Riskind \& Rholes, 1985). The validity of this model is 
reinforced by the associated low self-esteem (Brown \& Mankowski, 1993), psychomotor retardation (Velten, 1968; Teasdale \& Fogarty, 1979; Natale \& Boylan, 1980) and cortisol hypersecretion (Brown et al. 1993). Current psychological theories of the pathogenesis of depressive disorders have emphasized the role of deviant cognitive style, characterized by selfdeprecating thoughts, analogous to the some of the Velten statements, and the mood state induced by this procedure has been invoked to support cognitive models of the pathogenesis of depression (Riskind \& Rholes, 1985).

An understanding of the pathophysiology of mood disorders requires specification of the neural systems that mediate normal emotional response and the neurophysiological mechanisms by which these systems influence cognitive function. Animal studies suggest a critical involvement of the ventral prefrontal cortex in the regulation of emotion (Rolls, 1994). Consistent with this, activation of the orbitofrontal cortex has been observed during recall or imagination of sad events (Pardo et al. 1993, George et al. 1995), during evoked anxiety in phobic and obsessive-compulsive disorders (Rauch et al. 1994, 1995) and with the dysphoria of angina pectoris (Rosen et al. 1994). Lesions to the orbitofrontal cortex disrupt social and emotional regulation of behaviour in humans and monkeys (Butter et al. 1968; Damasio et al. 1990). However the relationship between affective disorders and orbitofrontal dysfunction remains unclear. The surgical procedure of subcaudate tractotomy, resulting in disconnection of the orbitofrontal cortex, is reported as effective in the treatment of severe resistant depression (Bridges et al. 1994). Curiously, functional abnormalities are only rarely reported in this region in imaging studies of depression (e.g. Mayberg et al. 1990; Goodwin et al. 1993).

We used a combined mood induction and cognitive activation paradigm to investigate the functional anatomy of elated and depressed mood in normal subjects. Combining these tasks provides a powerful tool to determine the interaction between mood and cognitive function.

\section{METHOD}

\section{Subjects}

Ten male volunteers aged between 18 and 35 years took part in the study, which was approved by the Hammersmith Hospital Ethics Committee and the Advisory Committee on the Administration of Radioactive Substances (ARSAC) UK. Subjects were recruited from the staff and students at London teaching hospitals, they were screened to exclude previous psychiatric disorder and drug use and were strongly righthanded as assessed by the Edinburgh inventory. Informed consent was obtained from all subjects.

\section{PET scanning techniques}

Regional cerebral blood flow was measured with a CTI model 953B PET Scanner (CTI, Knoxville, TN, USA), with the interplane septa retracted (Spinks et al. 1992). Following a 'slow bolus' infusion of $\mathrm{H}_{2}{ }^{15} \mathrm{O}$, integrated counts per pixel during the $90 \mathrm{~s}$ acquisition frame, corrected for background counts, provided an index of rCBF. Then $11.2 \mathrm{mCi}$ of $\mathrm{H}_{2}{ }^{15} \mathrm{O}$ was flushed with normal saline through a cannula in an antecubital vein over $20 \mathrm{~s}$ at $10 \mathrm{ml} / \mathrm{min}$ by an automatic pump. After a constant delay a rise in counts at the head was detected, which peaked between $30-40$ s in individual subjects. Although counts were collected for $90 \mathrm{~s}$, only the activity occurring during the rising phase of the head count curve contributes significantly to the signal in the final image (Silbersweig et al. 1993). Each subject underwent 12 scans, with a $10 \mathrm{~min}$ interval between scans. Correction for attenuation was made by performing a transmission scan with an exposed ${ }^{68} \mathrm{Ge} /{ }^{68} \mathrm{Ga}$ external ring source before each session and a $30 \mathrm{~s}$ frame for background activity correction was acquired before each infusion.

\section{Study design}

During each scan subjects performed either paced orthographic verbal fluency or word repetition tasks, generating or repeating one word every $5 \mathrm{~s}$, in a repeated $\mathrm{ABAB} \ldots$ design (Frith et al. 1991). In the verbal fluency condition subjects continued to generate words beginning with a given letter until they failed to respond within the time limit after which they were given a new letter. Subjects were studied in elated, neutral and depressed mood states. Mood 


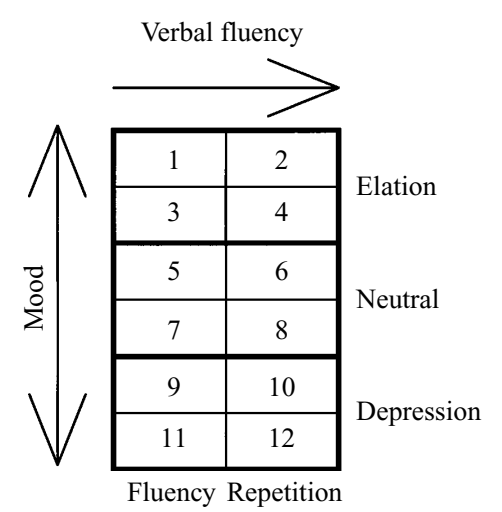

Fig. 1. Diagrammatic illustration of the study design. There are six scans in the verbal fluency condition and six in the repetition condition. These are subdivided into three blocks of four scans each in elated, neutral and depressed mood. The order of induced mood states was counterbalanced across subjects to avoid systematic time effects.

induction material was presented for $7.5 \mathrm{~min}$ prior to each scan. The study was divided into three blocks of four scans specific to each induced mood state (Fig. 1). This factorial design allows examination of the main effect of the verbal fluency task in the comparison of the verbal fluency and control conditions across all mood states, the main effect of mood state in the comparison of the elated and depressed mood and neutral mood states across task conditions and the interaction between verbal fluency and mood; i.e. the difference in verbal fluency activation in elated and depressed mood compared to neutral mood. The order of the mood states was counterbalanced across subjects to accommodate time dependent effects. All subjects were debriefed after the study.

\section{Mood induction paradigm}

Subjects were studied in the presence of low background noise and dimmed ambient lighting. A combination of the Velten, musical, social interaction and gift mood induction procedures were employed (Velten, 1968; Clark \& Teasdale, 1985; Gerrards-Hesse et al. 1994). Subjects were given explicit instructions to enter into the suggested emotional state. Elated, neutral and depressed mood induction statements, modified from Velten (1968), were presented on an Apple Macintosh microcomputer, at a rate of one statement every $30 \mathrm{~s}$. Subjects were played extracts of 'Russia under the Mongolian Yoke', from Prokofiev's music for the film 'Alexander Nevsky' (Clark, 1983), at half speed in the depressed condition; 'Stressbusters', an anodyne recording of popular classics, in the neutral condition; and Delibes' 'Coppelia' in the elated condition. The investigator adopted an appropriately cheerful, neutral or solemn manner. Subjects were presented with an unexpected gift of $£ 30$ at the beginning of the elated mood condition.

\section{Data analysis}

Image analysis was performed on a SPARC 10 workstation (Sun Microsystems Inc., Surrey, UK) using interactive image display software (ANALYZE, Biodynamic Research Unit, Mayo Clinic; Robb \& Hanson, 1990) and statistical parametric mapping (SPM software, MRC Cyclotron Unit, London, UK). Calculations and image matrix manipulations were performed in PRO MATLAB (Mathworks Inc., New York, USA).

\section{Image reconstruction}

Images were reconstructed into 31 slices by three-dimensional back projection using a Hanning filter with a cut-off frequency of 0.5 cycles per pixel. The resulting images consisted of $128 \times 128$ pixels of $2.006 \times 2.006 \mathrm{~mm}$ having a resolution of $8.5 \times 8.5 \times 4.3 \mathrm{~mm}$ full width at half maximum (FWHM).

\section{Image analysis}

The 31 original slices were interpolated to 43 planes in order to render the voxels approximately cubic. Images were automatically realigned to correct for head movement between scans (Woods et al. 1993) and transformed into a standard stereotactic space (Friston et al. 1991a). The stereotactically normalized images, consisting of 26 planes, correspond to the horizontal sections of the standard stereotactic atlas (Talairach \& Tournoux, 1988), each pixel represents $2 \times 2 \mathrm{~mm}$ with an interplanar distance of $4 \mathrm{~mm}$. The field of view in all subjects extended from $8 \mathrm{~mm}$ below to $56 \mathrm{~mm}$ above a line joining the anterior and posterior commissures. Images were smoothed with a Gaussian filter 10 pixels wide in order to suppress high frequency noise in the images and accomodate normal variability in functional and gyral anatomy for group analysis. 


\section{Stastistical analysis}

Differences in global activity within and between subjects were removed by analysis of covariance (ANCOVA) on a pixel by pixel basis with global counts as covariate and regional activity in each condition across subjects as treatment (Friston et al. 1990). The ANCOVA generated a mean rCBF value, normalized to $50 \mathrm{ml} / 100 \mathrm{ml} / \mathrm{min}$, and associated error variance for every pixel in each condition. This adjusted $\mathrm{rCBF}$ represents a weighted mean over a sphere of approximately $20 \mathrm{~mm}$. Differences between the adjusted mean pixel values across conditions were assessed using the $t$ statistic (Friston et al. 1991b), the resulting images of pixel $t$ values constitute a statistical parametric map $(\operatorname{SPM}(t))$. The omnibus significance of the SPMs was assessed by comparing the expected and observed distribution of the $t$ statistic under the null hypothesis of no treatment effect. The $\operatorname{SPM}(t) \mathrm{s}$ were additionally displayed as volume images of the highest $t$ values in three orthogonal projections and as surface renderings onto a standard cerebral cortex. $\operatorname{SPM}(t) \mathrm{s}$ were transformed to the Unit Gaussian distribution using a probability integral transform so that changes could be reported as $Z$ scores.

\section{RESULTS}

\section{Mood induction}

Nine of the 10 subjects reported subjective mood change during the mood induction procedure, reflected in highly significant change in scores on the PANAS (Watson et al. 1988) and ratings of elation and depression (Table 1). One subject reported no subjective change in mood and there was no change in his ratings; he was excluded from the subsequent analysis. There was no significant difference in the number of words generated in the verbal fluency task in different mood states, there were a total of six omissions in neutral and depressed mood and seven in elated mood.

\section{Comparison of $\mathrm{rCBF}$ in verbal fluency compared to repetition conditions}

The main effect of the verbal fluency task was examined by comparison of all scans in the verbal fluency and control conditions. Foci of maximal change in $\mathrm{rCBF}$ are displayed in Fig. 2
Table 1. Mean positive and negative affect scores on the Positive and Negative Affect Scale (PANAS; Watson et al. 1988) and mood ratings in depressed, neutral and elated mood conditions

\begin{tabular}{llllll}
\hline \hline $\begin{array}{l}\text { Induced } \\
\text { mood }\end{array}$ & \multicolumn{2}{c}{ PANAS scores } & & \multicolumn{2}{c}{ Elation depression } \\
\cline { 2 - 3 } \cline { 5 - 6 } & +ve (S.D.) & - ve (S.D.) & & Score (S.D.) & Score (S.D.) \\
\hline Depressed & $17 \cdot 3(5 \cdot 6)^{* * * *}$ & $18 \cdot 2(5 \cdot 7)^{* * * *}$ & $1.3(0 \cdot 6) \mathrm{NS}$ & $2 \cdot 7(1 \cdot 0)^{* * * *}$ \\
Neutral & $22.5(7 \cdot 0)$ & $11 \cdot 7(2 \cdot 6)$ & $1 \cdot 9(0 \cdot 7)$ & $1 \cdot 1(0 \cdot 4)$ \\
Elated & $32 \cdot 3(7 \cdot 6)^{* * *}$ & $11 \cdot 0(1 \cdot 4) \mathrm{NS}$ & $3 \cdot 4(0 \cdot 9)^{* * *}$ & $1 \cdot 0(0 \cdot 0) \mathrm{NS}$ \\
\hline \hline
\end{tabular}

Significance of change in elated and depressed mood compared to neutral mood: *** $P<0.0001$; NS Not significant.

PANAS norms for college students rating current mood under standard conditions (Watson et al. 1988): + ve mean $29 \cdot 7$ S.D. $7 \cdot 9$, - ve mean $14 \cdot 8$ S.D. $5 \cdot 4$. Depressed and elated mood induction were both associated with significant change in rated mood from the neutral condition.

and summarized in Table 2. Highly significant increases in $\mathrm{rCBF}(P<0.001)$ were observed in the verbal fluency condition in the left inferior frontal gyrus and dorsolateral prefrontal cortex, bilateral anterior cingulate and insula cortex anteriorly, the left angular gyrus posteriorly and the thalamus. There were relative decreases in $\mathrm{rCBF}(P<0.001)$ in right inferior and superior frontal gyri, bilaterally in superior and middle temporal gyri and in medial temporal, inferior parietal and occipital cortex.

\section{rCBF changes in elated and depressed mood}

The main effect of induced mood was examined by comparison of all scans in elated and depressed mood compared to the neutral mood. Bilateral orbitofrontal rCBF increases $(P<$ $0.001)$ were seen in both elated and depressed mood compared to the neutral condition (Fig. $3 a$ and $b$; Tables 3 and 4 ), and were significantly greater in elated mood than in depressed mood $(P<0 \cdot 0005)$. rCBF increases were also observed in the superior region of the left dorsolateral prefrontal cortex and right lateral premotor area in both elated and depressed mood. In depressed mood, rCBF increases were apparent in SMA and posterior cingulate cortex. In elated mood a focal $\mathrm{rCBF}$ increase was also present in the region of the posterior hypothalamus and midbrain and also in left superior frontal gyrus. Posteriorly $\mathrm{rCBF}$ was increased in the right lateral parietal cortex.

Decreased rCBF $(P<0 \cdot 001)$ was observed in the right caudate nucleus in both elated and 
Table 2. Comparison of verbal fluency and repetition conditions: foci of significant $r$ CBF change

\begin{tabular}{|c|c|c|c|c|c|c|}
\hline \multirow[b]{2}{*}{ Location } & \multirow{2}{*}{$\begin{array}{l}\text { Left/ } \\
\text { Right }\end{array}$} & \multirow{2}{*}{$\begin{array}{l}\text { Brodmann's } \\
\text { area }\end{array}$} & \multicolumn{3}{|c|}{ Talairach coordinates } & \multirow[b]{2}{*}{$Z$ value } \\
\hline & & & $x$ & $y$ & $z$ & \\
\hline \multicolumn{7}{|l|}{$\mathrm{rCBF}$ increases } \\
\hline $\begin{array}{l}\text { Anterior cingulate } \\
\text { gyrus }\end{array}$ & $\mathrm{L}$ & 32 & -4 & 18 & 36 & $10 \cdot 1$ \\
\hline $\begin{array}{l}\text { Middle frontal } \\
\text { gyrus }\end{array}$ & $\mathrm{L}$ & 46 & -32 & 44 & 20 & 6.36 \\
\hline Middle frontal & $\mathrm{L}$ & 10 & -24 & 36 & -8 & $4 \cdot 02$ \\
\hline gyrus & $\mathrm{R}$ & 10 & 20 & 34 & -4 & $3 \cdot 47$ \\
\hline $\begin{array}{l}\text { Inferior frontal } \\
\text { gyrus }\end{array}$ & $\mathrm{L}$ & 44 & -36 & 4 & 28 & 6.94 \\
\hline \multirow[t]{2}{*}{ Anterior insula } & $\mathrm{L}$ & & -30 & 18 & 4 & $7 \cdot 71$ \\
\hline & $\mathrm{R}$ & & 22 & 16 & 4 & $4 \cdot 23$ \\
\hline $\begin{array}{l}\text { Medial premotor } \\
\text { cortex (SMA) }\end{array}$ & $\mathrm{L}$ & 6 & -10 & 2 & 56 & $7 \cdot 85$ \\
\hline $\begin{array}{l}\text { Angular gyrus } \\
\text { Thalamus }\end{array}$ & $\mathrm{L}$ & 39 & -28 & -56 & 36 & $3 \cdot 28$ \\
\hline \multicolumn{7}{|l|}{ rCBF decreases } \\
\hline Superior frontal & $\mathrm{R}$ & 10 & 6 & 58 & 4 & 3.89 \\
\hline gyrus & $\mathrm{R}$ & 9 & 5 & 50 & 32 & $4 \cdot 07$ \\
\hline $\begin{array}{l}\text { Inferior frontal } \\
\text { gyrus }\end{array}$ & $\mathrm{R}$ & $44 / 45$ & 48 & 12 & 20 & 3.74 \\
\hline Superior temporal & $\mathrm{R}$ & 22 & 46 & -12 & 4 & $7 \cdot 25$ \\
\hline \multirow{3}{*}{ gyrus } & $\mathrm{L}$ & 22 & -46 & -16 & 8 & $6 \cdot 54$ \\
\hline & $\mathrm{R}$ & 22 & 46 & -48 & 16 & $7 \cdot 84$ \\
\hline & $\mathrm{L}$ & 22 & -52 & -32 & 12 & $7 \cdot 07$ \\
\hline Middle temporal & $\mathrm{L}$ & 39 & -48 & -60 & 12 & $8 \cdot 40$ \\
\hline gyrus & $\mathrm{R}$ & 37 & 44 & -56 & 4 & $7 \cdot 40$ \\
\hline Inferior parietal & $\mathrm{L}$ & 40 & -56 & -42 & 28 & 4.04 \\
\hline cortex & $\mathrm{R}$ & 40 & 50 & -30 & 32 & $6 \cdot 31$ \\
\hline Medial temporal & $\mathrm{R}$ & 36 & 22 & -40 & -8 & 4.73 \\
\hline cortex & $\mathrm{L}$ & 19 & -32 & -44 & 0 & 3.53 \\
\hline \multirow[t]{2}{*}{ Occipital cortex } & $\mathrm{L}$ & 18 & -4 & -92 & 12 & $3 \cdot 16$ \\
\hline & $\mathrm{L}$ & 19 & -34 & -80 & 24 & 3.64 \\
\hline
\end{tabular}

The co-ordinates of the foci of maximal significant change of $\mathrm{rCBF}(P<0.001)$ in the standard stereotaxic space of Talairach \& Tournoux (1988) are given in millimeters.

(a)

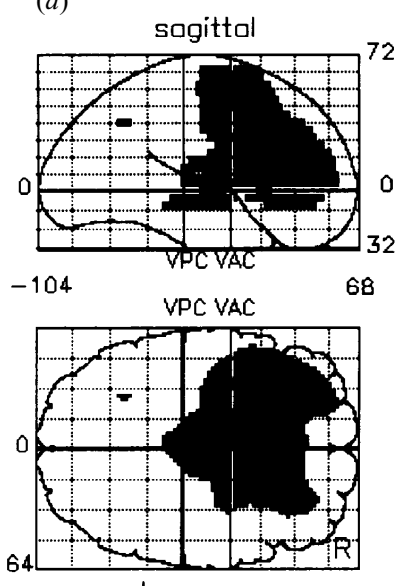

transverse (b)

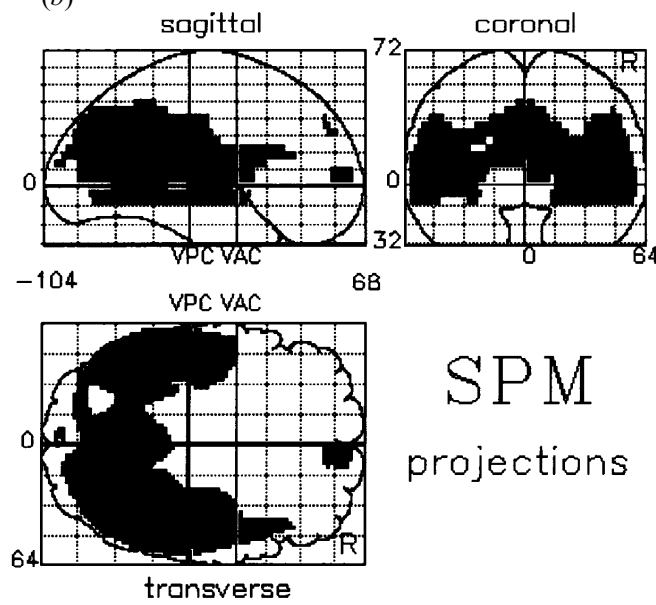

FIG. 2. Regional brain activity associated with the verbal fluency task. Statistical parametric maps (SPMs) show regional cerebral blood flow $(\mathrm{rCBF})$ changes in word generation compared to word repetition scans. The SPMs illustrate: $(a)$ increases; and $(b)$ decreases of rCBF. Pixels exceeding an uncorrected threshold of significance $P<0.001$ are displayed on sagittal, coronal and transverse projections of a standard brain (Talairach \& Tournoux, 1988), the left side of the brain is on the left side of the projections. The co-ordinates of the foci of maximal change of $\mathrm{rCBF}$ are given in Table 1. 
(a)
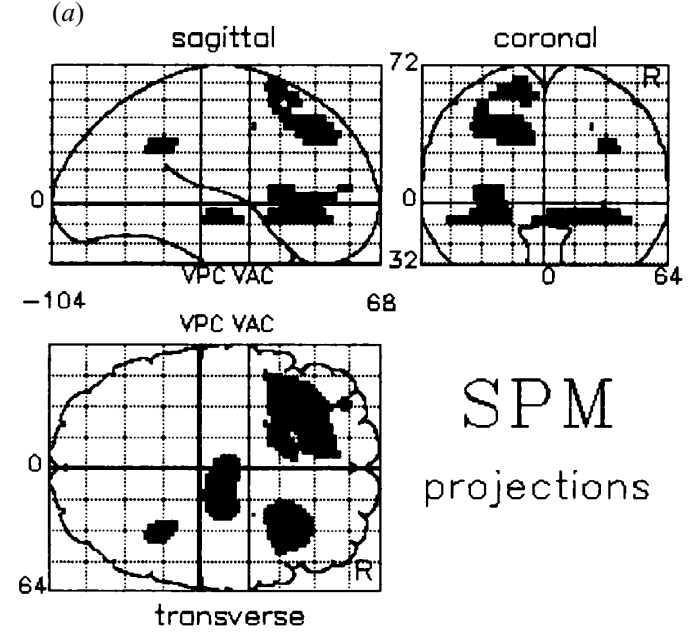

68

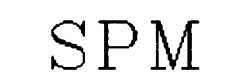

projections
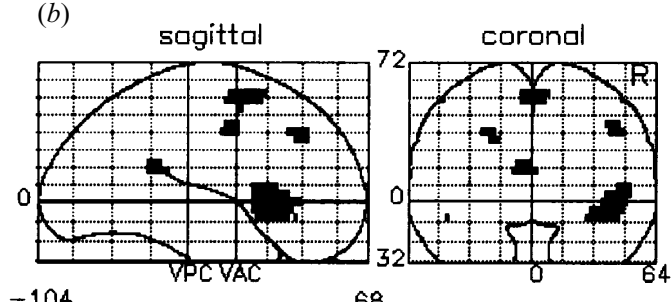

$-104 \quad$ VPC VAC

68
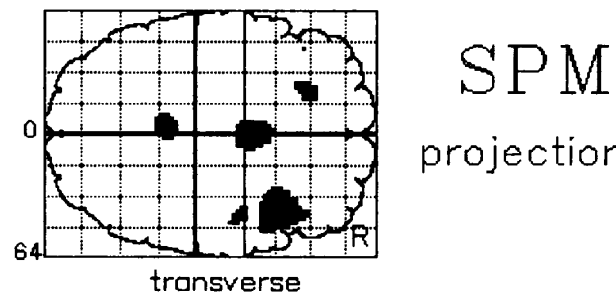

projections

(1)
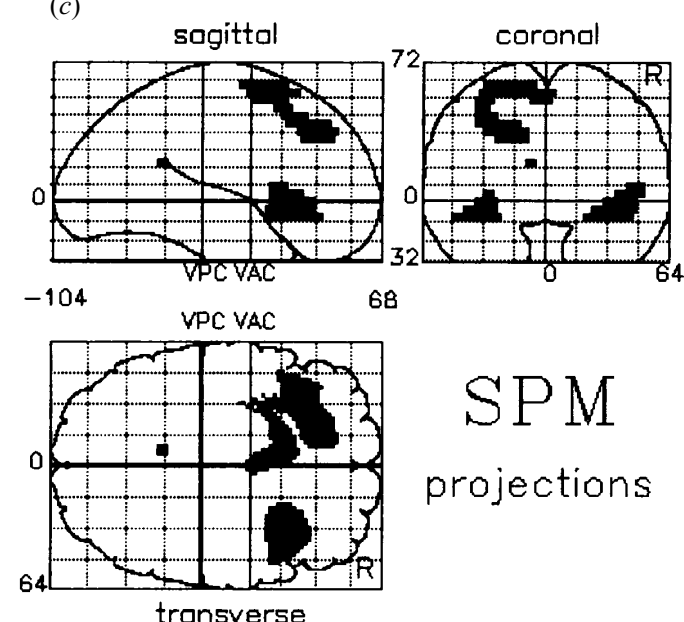

projections

FIG. 3. Regional brain activity associated with induced mood states. SPMs illustrate increases of rCBF in: $(a)$ elated mood compared to neutral mood; $(b)$ depressed mood compared to neutral mood; and, $(c)$ activation common to both elated and depressed mood states compared to neutral mood. Pixels exceeding an uncorrected threshold of significance $P<0 \cdot 001$ are illustrated as in Fig.

1. The coordinates of the foci of maximal change of $\mathrm{rCBF}$ in elated and depressed mood compared to neutral mood are given in Table 2.

depressed mood. Depressed mood was associated with decreased $\mathrm{rCBF}$ in the right dorsolateral and bilateral rostral medial prefrontal cortex. Elated mood was associated with decreased $\mathrm{rCBF}$ in the middle and inferior temporal and posterior cingulate cortex and the thalamus.

When the combined elated and depressed mood conditions were compared with the neutral condition (Fig. 3c) rCBF increases attained highest significance in the lateral orbitofrontal cortex (BA 47) bilaterally.

\section{Interaction between induced mood and cognitive activation}

To examine the interaction between mood and the cognitive task, the difference between verbal fluency activation in elated (or depressed mood) and neutral mood was determined. The network activated by the verbal fluency task defines regions in which brain activity associated with the cognitive task may be modulated by the induced mood states. These critical comparisons were therefore constrained to voxels at which 
Table 3. Comparison of depressed and neutral mood: foci of significant $r C B F$ change

\begin{tabular}{|c|c|c|c|c|c|c|}
\hline \multirow[b]{2}{*}{ Location } & \multirow{2}{*}{$\begin{array}{l}\text { Left/ } \\
\text { Right }\end{array}$} & \multirow{2}{*}{$\begin{array}{l}\text { Brodmann's } \\
\text { area }\end{array}$} & \multicolumn{3}{|c|}{ Talairach coordinates } & \multirow[b]{2}{*}{$Z$ value } \\
\hline & & & $x$ & $y$ & $z$ & \\
\hline \multicolumn{7}{|l|}{$\mathrm{rCBF}$ increases } \\
\hline Inferior frontal & $\mathrm{R}$ & 47 & 36 & 20 & -8 & 3.74 \\
\hline \multirow{2}{*}{ gyrus } & $\mathrm{L}$ & 47 & -44 & 32 & -8 & 3.09 \\
\hline & $\mathrm{R}$ & 45 & 46 & 16 & 4 & $3 \cdot 55$ \\
\hline $\begin{array}{l}\text { Middle frontal } \\
\text { gyrus }\end{array}$ & $\mathrm{L}$ & 9 & -24 & 32 & 36 & $3 \cdot 27$ \\
\hline $\begin{array}{l}\text { Lateral premotor } \\
\text { cortex }\end{array}$ & $\mathrm{R}$ & 6 & 44 & 0 & 36 & $3 \cdot 29$ \\
\hline SMA & & 6 & 0 & 6 & 56 & $3 \cdot 77$ \\
\hline Post. cingulate & & 23 & -4 & -38 & 16 & 3.77 \\
\hline gyrus & & 31 & 0 & -32 & 40 & $2 \cdot 91$ \\
\hline \multicolumn{7}{|l|}{ rCBF decreases } \\
\hline Superior frontal & $\mathrm{R}$ & 10 & 6 & 48 & -4 & $4 \cdot 06$ \\
\hline gyrus & $\mathrm{L}$ & 10 & -8 & 58 & -4 & $3 \cdot 84$ \\
\hline Middle frontal & $\mathrm{R}$ & 46 & 28 & 28 & 24 & $3 \cdot 30$ \\
\hline Caudate nucleus & $\mathrm{R}$ & & 18 & -8 & 24 & 3.09 \\
\hline
\end{tabular}

The co-ordinates of the foci of maximal significant change of $\mathrm{rCBF}(P<0 \cdot 001)$ in the standard stereotaxic space of Talairach $\&$ Tournoux (1988) are listed as in Table 2.

Table 4. Comparison of elated and neutral mood: foci of significant $r C B F$ change

\begin{tabular}{|c|c|c|c|c|c|c|}
\hline \multirow{2}{*}{$\begin{array}{l}\text { Location } \\
\text { value }\end{array}$} & \multirow{2}{*}{$\begin{array}{l}\text { Left/ } \\
\text { Right }\end{array}$} & \multirow{2}{*}{$\begin{array}{l}\text { Brodmann's } \\
\text { area }\end{array}$} & \multicolumn{3}{|c|}{ Talairach coordinates } & \multirow[b]{2}{*}{$Z$} \\
\hline & & & $x$ & $y$ & $z$ & \\
\hline \multicolumn{7}{|l|}{ rCBF increases } \\
\hline Inferior frontal & $\mathrm{L}$ & 47 & -30 & 28 & -8 & $4 \cdot 17$ \\
\hline \multirow[t]{2}{*}{ gyrus } & $\mathrm{R}$ & 47 & 30 & 24 & -8 & $4 \cdot 47$ \\
\hline & $\mathrm{L}$ & 47 & -26 & 28 & 0 & 3.94 \\
\hline Middle frontal & $\mathrm{L}$ & 10 & -34 & 52 & 8 & $3 \cdot 28$ \\
\hline gyrus & $\mathrm{L}$ & 8 & -30 & 32 & 40 & 4.78 \\
\hline Superior frontal & $\mathrm{L}$ & 9 & -16 & 40 & 36 & $4 \cdot 33$ \\
\hline gyrus & $\mathrm{L}$ & $8 / 6$ & -14 & 24 & 56 & 3.59 \\
\hline Lateral premotor & $\mathrm{R}$ & 6 & 24 & 4 & 40 & 3.09 \\
\hline \multirow[t]{2}{*}{ cortex } & $\mathrm{L}$ & 6 & -36 & 14 & 48 & $3 \cdot 24$ \\
\hline & $\mathrm{L}$ & 6 & -24 & 16 & 56 & 3.31 \\
\hline $\begin{array}{l}\text { Lateral parietal } \\
\text { cortex }\end{array}$ & $\mathrm{R}$ & 40 & 34 & -46 & 28 & 3.85 \\
\hline Hypothalamus & & & 2 & -12 & -8 & 3.98 \\
\hline \multicolumn{7}{|l|}{ rCBF decreases } \\
\hline Fusiform gyrus & $\mathrm{L}$ & 37 & -32 & -44 & -8 & $3 \cdot 46$ \\
\hline $\begin{array}{l}\text { Middle temporal } \\
\text { gyrus }\end{array}$ & $\mathrm{R}$ & 21 & 56 & -34 & -8 & 3.97 \\
\hline $\begin{array}{l}\text { Post. cingulate } \\
\text { gyrus }\end{array}$ & $\mathrm{R}$ & $23 / 31$ & 20 & -56 & 20 & 3.53 \\
\hline Thalamus & & & 0 & -18 & 16 & $3 \cdot 29$ \\
\hline Caudate nucleus & $\mathrm{R}$ & & 16 & -12 & 24 & $3 \cdot 48$ \\
\hline
\end{tabular}

The co-ordinates of the foci of maximal significant change of $\mathrm{rCBF}(P<0 \cdot 001)$ in the standard stereotaxic space of Talairach \& Tournoux (1988) are listed as in Table 3.

significant $\mathrm{rCBF}$ increases were observed in the verbal fluency condition. Activation of the verbal fluency network was attenuated by both elated and depressed mood. No enhancement of acti- vation in this network was observed in either induced mood state.

In the depressed mood state activation was attenuated $(P<0.0005)$ throughout the left 
(a)

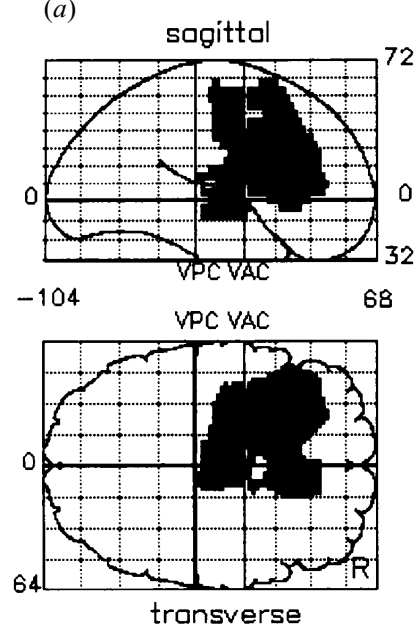

(b)

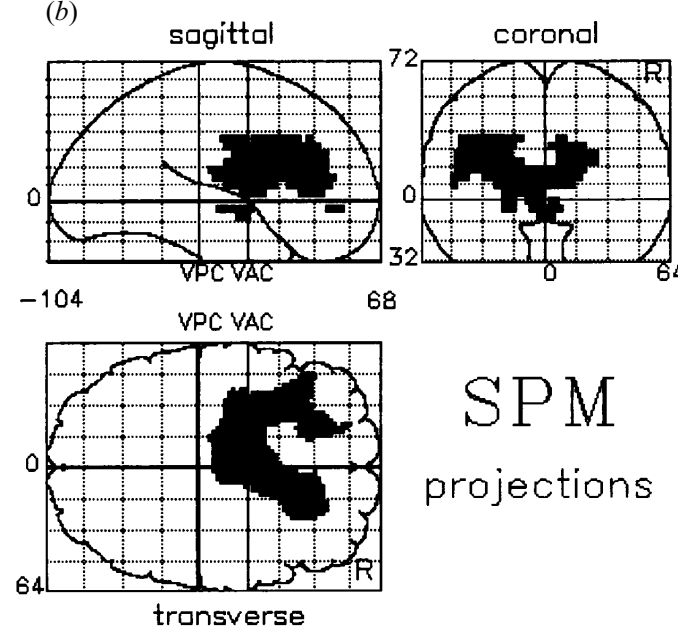

(c)

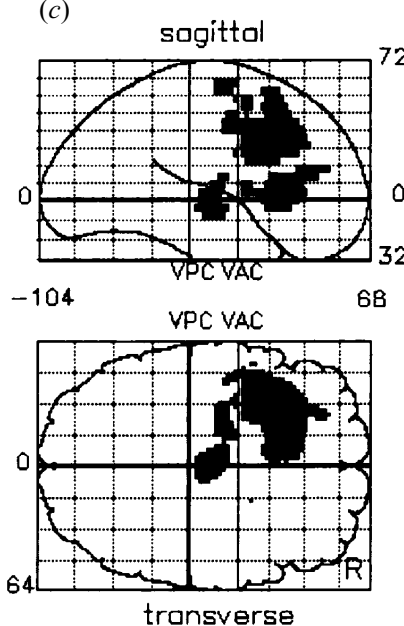

coranal

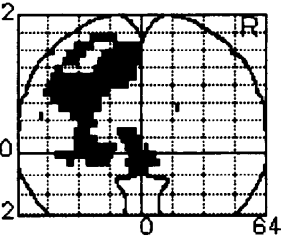

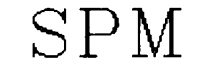

projections

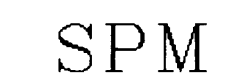

projections (d)
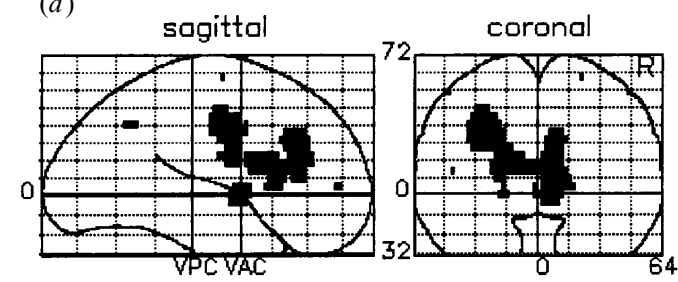

$-104$

VPC VAC

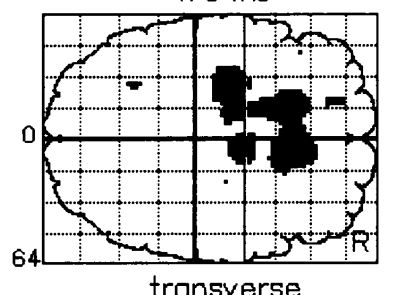

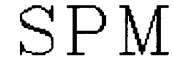

projections

FIG. 4. Interaction between mood and cognitive activation. SPMs illustrate: $(a)$ attenuation of verbal fluency activation by depressed mood (the difference between verbal fluency activation compared to repetition in depressed and neutral mood), activation of the network engaged by word generation is extensively attenuated; $(b)$ direct comparison of verbal fluency scans in depressed and neutral mood, (decreased rCBF in depressed mood in this comparison is attributable exclusively to changes in the verbal fluency condition); $(c)$ attenuation of verbal fluency activation by elated mood (activation is attenuated in prefrontal and premotor cortex as in depressed mood but not in the anterior cingulate cortex); $(d)$ comparison of rCBF differences in $(a)$ and $(c)$ illustrates attenuation of verbal fluency activation in anterior cingulate cortex specific to depressed mood. Pixels exceeding an uncorrected threshold of significance $P<0.0005$ are illustrated as in Fig. 1.

prefrontal and premotor areas and in the right anterior cingulate cortex and thalamus (Figs. $4 a$ and 5). A similar distribution of decreased $\mathrm{rCBF}$ in the depressed mood state $(P<0.005)$ is observed in a direct comparison of $\mathrm{rCBF}$ in the verbal fluency condition in depressed and neutral mood (Fig. 4b). In elated mood activation of this network was also attenuated in the left prefrontal cortex, premotor cortex and thalamus (Fig. 4c). Comparison of these patterns of attenuated verbal fluency activation reveals that the attenuated activation in the anterior cingulate cortex is specific to depressed mood (Fig. $4 d$ ). Mean CBF values in the anterior cingulate 
Verbal fluency activation

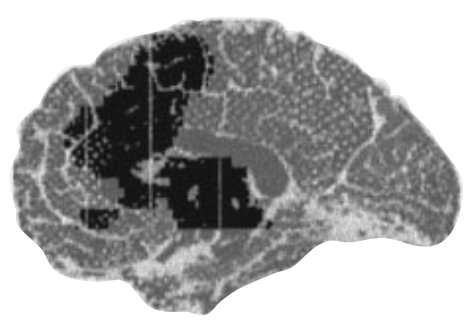

Right

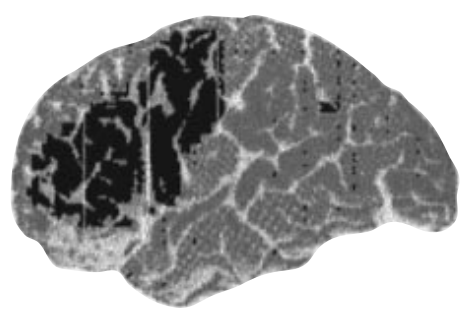

Left
Attenuation: depressed mood
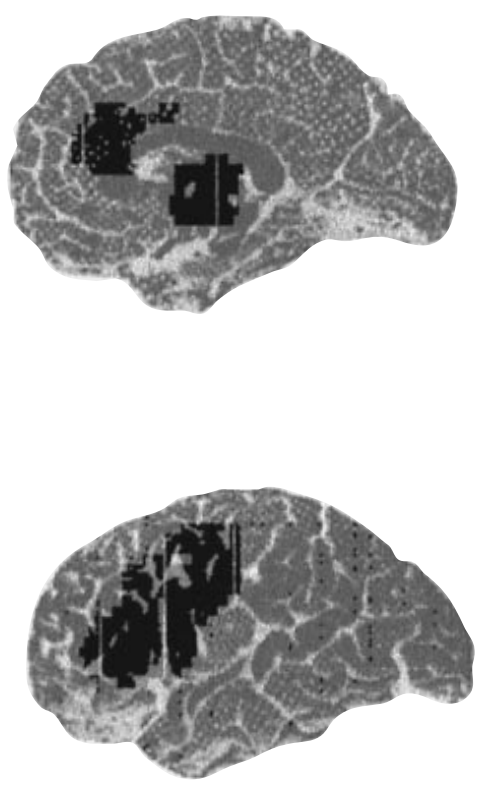

FIG. 5. Verbal fluency activation (left of figure) and areas of attenuated activation in depressed mood (right of figure) are displayed rendered onto a standard brain surface. The medial surface of the right hemisphere (top) and the lateral surface of the left hemisphere (bottom) are illustrated.

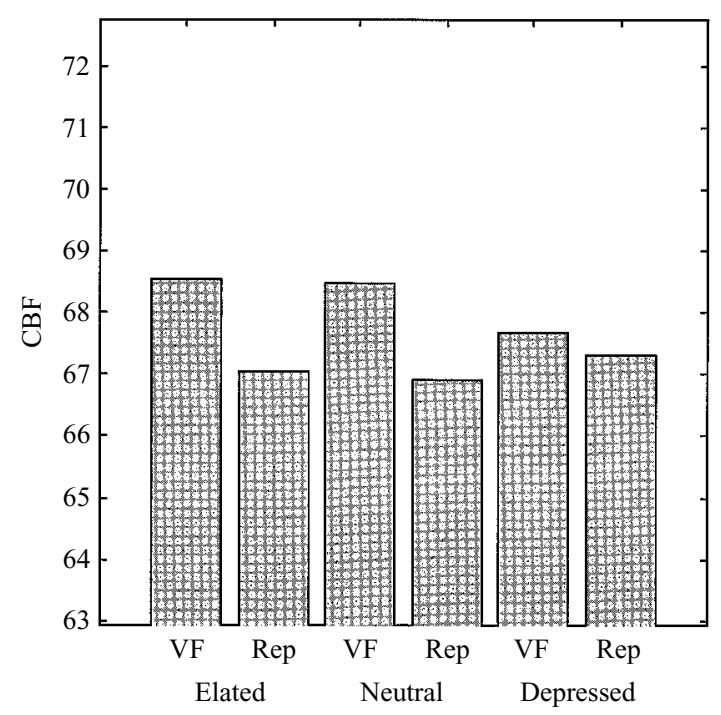

FIG. 6. Adjusted CBF values for the right anterior cingulate cortex in verbal fluency (VF) and repetition (Rep) conditions are shown in each mood state. Mean CBF values were normalized to a global mean of $50 \mathrm{ml} / 100 \mathrm{ml} / \mathrm{min}$.

cortex at the focus of maximal significant attenuation of activation are illustrated in Fig. 6.

\section{DISCUSSION}

The aims of the present study were to determine which neural systems mediate distinct mood states and to determine the locus of interaction, at the neurophysiological level, between affective and cognitive function. Bilateral activation of the orbitofrontal cortex in both elated and depressed mood suggests that this region is involved in the representation of emotion. The interaction of mood and cognition revealed a striking pattern of attenuation of verbal fluency induced $\mathrm{rCBF}$ increases, in the depressed mood state, that mirrors the decreased $\mathrm{rCBF}$ in patients with psychomotor retardation (Bench et al. 1993). These findings provide neurophysiological support for the depressed mood induction procedure as a model of the psychological and neurophysiological dysfunctions seen in retarded depression (Clark, 1983).

\section{Mood induction}

Effective mood induction techniques rely on the co-operation and ability of subjects to 'get into' the appropriate mood state and consequently are ineffective in a proportion of subjects. The 
Velten procedure has been widely employed and between 30 and $50 \%$ of subjects fail to experience a measurable change in mood (Polivy \& Doyle, 1980; Teasdale \& Taylor, 1981; Sutherland et al. 1982; Teasdale \& Russell, 1983). Mood induction with music is effective in a greater proportion of subjects (Sutherland et al. 1982; Clark, 1983). In our study the combined mood induction procedure was ineffective in only one subject.

\section{rCBF correlates of induced mood}

Bilateral $\mathrm{rCBF}$ increases were observed in lateral orbitofrontal cortex associated with both elated and depressed mood, indicating that both mood states engage a common neural substrate. This is consistent with electrophysiological studies in the monkey which demonstrate that cells responding to positive and negative affective stimuli are intermingled in the same neuronal population in the orbitofrontal cortex (Thorpe et al. 1983).

Activation of the orbitofrontal cortex has been found in previous functional imaging studies that have manipulated affective states. Subjects imaged in a resting state and during dysphoric mood induction using an autobiographical recollection technique (Pardo et al. 1993), showed bilateral activation of the lateral orbitofrontal cortex. Mood induction involving a combination of autobiographical recollection and visual inspection of mood congruent facial expression (George et al. 1995), is reported as activating the ventral cingulate and rostral medial prefrontal cortex during depressed mood induction compared to a control condition. No significant change in $\mathrm{rCBF}$ was associated with elated mood induction in the analogous comparison. However, the experimental design of the latter experiment confounds changes in neural activity associated with recollection with changes associated with the induced mood. Activation of the orbital cortex has also been reported in association with induction of anxiety and visceral pain. In phobic patients, anxiety induced by exposure to feared stimuli was associated with lateral orbitofrontal activation (Rauch et al. 1995) and precipitation of angina pectoris in cardiac patients (Rosen et al. 1994) was associated with extensive activation of the ventral cingulate and lateral orbitofrontal cortex. It should be noted that the full ventral extent of the orbitofrontal activations could not be determined in the present study due to the limited field of view of the PET camera.

The independent activation of lateral and medial orbital cortex in the present, and other, studies is strong evidence for their differential role in the regulation of emotion. A significant difference between this study and previous studies of mood induction is that we studied patients performing a cognitive task after the induction of a mood state. Previous experiments have all studied subjects during the induction of a mood state. These different findings might suggest a dissociation between the functional role of medial and lateral orbitofrontal cortex. The anterior cingulate and medial prefrontal cortex may mediate affective reactivity to emotionally salient stimuli while the lateral orbitofrontal cortex may have a more general associative function in emotional responsiveness.

A highly significant activation was also observed in the region of the posterior hypothalamus in the elated mood. This region has reciprocal anatomical connections with the orbitofrontal cortex (Neafsey et al. 1986) and plays an important role in emotional expression. Activation in this area has also been observed in the dysphoric state associated with induction of angina pectoris (Rosen et al. 1994).

Mood induction was associated with increased rCBF in medial and lateral premotor areas and superior prefrontal cortex. Although responses were paced to equate net verbal output across conditions the affective intonation and prosody of responses in induced mood states inevitably reflect the current mood. This mood congruent behaviour is an implicit response component of the mood induction procedure. Enhanced premotor activation has previously been observed in association with auditory-verbal imagery, in which subjects generated inner speech with an alien intonation (McGuire et al. 1996). Increased premotor $\mathrm{rCBF}$ in both elated and depressed mood in this study may therefore reflect activations related to the mood congruent response characteristics of the induced mood state.

\section{Interaction with cognitive function}

A consistent finding in functional imaging studies of mood disorders has been the distributed nature of $\mathrm{rCBF}$ changes in brain regions 
associated with sensori-motor and cognitive function. One interpretation of these changes is that they reflect the interaction between mood and baseline activity in these systems. The present study was explicitly designed to investigate the interaction between induced mood and cognitive activation by a verbal fluency task, a cognitive task that engages neural systems shown to be affected in depression (Frith et al. $1991 a, b$; Bench et al. 1993).

The verbal fluency task, in this and other studies, activates a network of anterior and posterior cortical areas associated with language function (Petersen et al. 1989; Wise et al. 1991; Frith et al. 1991 $a, b$; Raichle et al. 1994; Warburton et al. 1995). Activation of the cortical network engaged by verbal fluency was significantly attenuated in the depressed mood state, from the inferior frontal gyrus to the precentral gyrus and SMA, and in dorsolateral prefrontal and anterior cingulate cortex. Attenuation of activation in the elated mood condition was also observed in this network, in the SMA and lateral premotor cortex and dorsolateral prefrontal cortex. Comparison of the patterns of attenuated activation in elation and depression demonstrate that the $\mathrm{rCBF}$ changes in the anterior cingulate cortex are specific to depression.

Both mood states were associated with orbitofrontal and dorsal prefrontal activation. Cognitive changes associated with elation have elicited less interest than those associated with depression, though pathologically elevated mood is accompanied by marked impairment of cognitive and attentional function. Faster writing speed and quicker decision times are found in elated mood states (Velten, 1968), performance on cognitive tasks, however, can be impaired (Basso et al. 1994). The attenuation of activation in the anterior cingulate gyrus specific to depressed mood may reflect the motivational impairment that is characteristic of depressed mood. Decreased rCBF was also apparent in the rostral medial prefrontal cortex in the depressed mood condition compared to both neutral and elated mood. $\mathrm{rCBF}$ decreases in this region correlated with cognitive and attentional impairment in depressed patients (Bench et al. 1993; Dolan et al. 1995).

\section{Depression and cognitive function}

Similar patterns of cognitive impairment have been demonstrated in both clinical depression and depressed mood and motivational and attentional impairments constitute core features of both conditions (Ellis et al. 1984, 1985; Radenhausen \& Anker, 1988). Decreased prefrontal $\mathrm{rCBF}$ is a common finding in depression (Baxter et al. 1989; Austin et al. 1992; Bench et al. 1993). Attenuated activation in the anterior cingulate, prefrontal and premotor cortex associated with depressed mood in the present experiment corresponds to the pattern of decreased $\mathrm{rCBF}$ found in depressed patients (Bench et al. 1993). Decreased rCBF in dorsolateral prefrontal and premotor cortex correlated with psychomotor retardation whereas decreases in medial prefrontal cortex correlated with cognitive impairment. A testable hypothesis is that prefrontal rCBF decreases in depression may represent neural correlates of the subjective experience of diminished spontaneous thought and inner speech that is characteristic of a common manifestation of the condition.

Bench et al. (1993) also noted decreased anterior cingulate $\mathrm{rCBF}$ in a direct comparison of depressed and normal subjects. A similar pattern of dorsal cingulate and medial prefrontal rCBF decreases was also associated with depression in Parkinsonian patients (Ring et al. 1994), where the decrease in rCBF extended to the most ventral anterior cingulate gyrus. In the present study attenuation of activation in the anterior cingulate cortex was specific to depressed mood. In the light of the consistent finding of decreased cingulate $\mathrm{rCBF}$ in different groups of depressed patients in this laboratory we suggest that anterior cingulate dysfunction may reflect a fundamental neurophysiological component of depression.

The anterior cingulate cortex is functionally heterogenous with at least three subdivisions recognized on the basis of its anatomical connectivity; an affective, a cognitive and a motor component (Devinsky et al. 1995). The affective component comprises the most ventral anterior cingulate cortex corresponding to Brodmanns' areas 33, 25 and rostral areas 32 and 24. These areas project to lateral orbitofrontal cortex, limbic striatum and brainstem autonomic centres (Kunishio \& Haber, 1994) 
and correspond to the areas activated during mood induction and the dysphoria of angina (George et al. 1995; Rosen et al. 1994). Electrical stimulation in this area evokes prominent behavioural and autonomic responses (Kaada, 1949). Decreased resting rCBF in this region has been reported in depression associated with Parkinson's disease (Mayberg et al. 1990; Ring et al. 1994) and increased rCBF associated with recovery from depression (Goodwin et al. 1993). The cognitive and motor components comprise caudal areas 24 and 32 . These areas are activated by somatic pain (Jones et al. 1991) and tasks involving attention and response selection (e.g. Pardo et al. 1990; Frith et al. 1991a) and correspond to the areas in which decreased $\mathrm{rCBF}$ has consistently been observed in depression (Bench et al. 1992, Ring et al. 1994).

Observations on patients with anterior cingulate lesions provide an important source of converging evidence to that of functional imaging data. Lesions in this structure are associated with 'diminished motivation, lethargy, loss of interest ... and decreased affective range' (Devinsky et al. 1995) analogous to the core symptoms of depression. The function of anterior cingulate cortex is itself regulated by ascending monoaminergic systems. It receives a dopaminergic innervation from the ventral tegmental area (Lindvall \& Bjorkland, 1983) and serotonergic innervation from the raphe nuclei (Anden et al. 1965). Dopaminergic deafferentation of the forebrain following hypothalamic lesions results in an analogous abulic syndrome that is partially reversible by dopaminergic agonists (Ross \& Stewart, 1981).

Psychological theories of depression have emphasized the significance of deviant cognitive attributions in the aetiology of depression (Beck, 1967). It is self evident that both biological and psychological causes of depression must inevitably be expressed through dysfunction at the level of neurophysiology. The present study demonstrates that depressed mood in normal subjects attenuates neural activation in prefrontal and anterior cingulate areas in which decreased neural activity has been observed in depressed patients (Bench et al. 1992, 1993).

Activation of the lateral orbitofrontal cortex in both depressed and elated mood states is consistent with extensive previous evidence in man and other animals, indicating a central role for this region in affective behaviour (Rolls et al. 1994). Within this system qualitatively different emotional responses may be represented by distinct patterns of neural discharge, analagous to the coding of different limb movements as specific patterns of activity within the same neuronal population (Fetz, 1993). We suggest that the present findings are consistent with modulation of distant functional systems by activity in the orbitofrontal cortex associated with emotional states.

Initial exploratory studies in this laboratory have now demonstrated consistent functional abnormalities of the anterior cingulate cortex in clinical depression and induced depressed mood states. By virtue of its functional subdivisions affective, cognitive and psychomotor symptoms may reflect specific regional dysfunction of this structure.

This work was carried out at the MRC Cyclotron Unit, Hammersmith Hospital. Professor Dolan and Professor Frith are supported by the Wellcome Trust. Dr Baker is a Wellcome Trust Research Fellow.

\section{REFERENCES}

Anden, N. E., Dahlstrom, A., Fuxe, K. \& Larsson, K. (1965). Mapping out of catecholamine and 5-hydroxytryptamine neurons innervating the telencephalon and diencephalon. Life Sciences $\mathbf{4}$, $1275-1279$

Austin, M. P., Dougall, N., Ross, M., Murray, C., O’Carroll, R. E., Moffoot, A., Ebmeier, K. P. \& Goodwin, G. M. (1992). Single photon emission tomography with ${ }^{99 \mathrm{~m}} \mathrm{Tc}$-exametazime in major depression and the pattern of brain activity underlying the psychotic/neurotic continuum. Journal of Affective Disorders 26, 31-43.

Basso, M. R., Schefft, B. K. \& Hoffmann, R. G. (1994). Moodmoderating effects of affect intensity on cognition: sometimes euphoria is not beneficial and dysphoria is not detrimental. Journal of Personality and Social Psychology 66, 363-368.

Baxter, L. R., Schwartz, J. M., Phelps, M. E., Mazziotta, J. C., Guze, B. H., Selin, C. E., Gerner, R. H. \& Sumida, R. M. (1989). Reduction of prefrontal glucose metabolism common to three types of depression. Archives of General Psychiatry 46, 243-250.

Beck, A. T. (1967). Depression: Clinical, Experimental and Theoretical Aspects. Harper and Row: New York.

Bench, C. J., Friston, K. J., Brown, R. G., Scott, L. C., Frackowiak, R. S. \& Dolan, R. J. (1992). The anatomy of melancholia-focal abnormalities of cerebral blood flow in major depression. Psychological Medicine 22, 607-615.

Bench, C. J., Friston, K. J., Brown, R. G., Frackowiak, R. S. \& Dolan, R. J. (1993). Regional cerebral blood flow in depression measured by positron emission tomography: the relationship with clinical dimensions. Psychological Medicine 23, 579-590.

Bridges, P. K., Bartlett, J. R., Hale, A. S., Poynton, A. M., Malizia, A. L. \& Hodgkiss, A. D. (1994). Psychosurgery: stereotactic subcaudate tractomy. An indispensable treatment. British Journal of Psychiatry 165, 599-611. 
Brown, J. D. \& Mankowski, T. A. (1993). Self-esteem, mood, and self-evaluation: changes in mood and the way you see you. Journal of Personality and Social Psychology 64, 421-430.

Brown, W. A., Sirota, A. D., Niaura, R. \& Engebretson, T. O. (1993). Endocrine correlates of sadness and elation. Psychosomatic Medicine 55, 458-467.

Butter, C. M., Mishkin, M. \& Mirsky, A. F. (1968). Emotional responses toward humans in monkeys with selective frontal lesions. Physiology and Behaviour 3, 213-215.

Clark, D. M. (1983). On the induction of depressed mood in the laboratory: Evaluation and comparison of the effects of the Velten and musical procedures. Advances in Behaviour Research and Therapy 5, 27-49.

Clark, D. M. \& Teasdale, J. D. (1985). Constraints on the effects of mood on memory. Journal of Personality and Social Psychology $\mathbf{4 8}$, 1595-1608.

Damasio, A. R., Tranel, D. \& Damasio, H. (1990). Individuals with sociopathic behavior caused by frontal damage fail to respond autonomically to social stimuli. Behavioural Brain Research 41, 81-94.

Devinsky, O., Morrell, M. J. \& Vogt, B. A. (1995). Contributions of anterior cingulate cortex to behaviour. Brain 118, 279-306.

Dolan, R. J., Bench, C. J., Brown, R. G., Scott, L. C., Friston, K. J. \& Frackowiak, R. S. (1992). Regional cerebral blood flow abnormalities in depressed patients with cognitive impairment. Journal of Neurology, Neurosurgery and Psychiatry 55, 768-773.

Dolan, R. J., Bench, C. J., Brown, R. G., Scott, L. C. \& Frackowiak, R. S. (1994). Neuropsychological dysfunction in depression: the relationship to regional cerebral blood flow. Psychological Medicine 24, 849-857.

Dolan, R. J., Fletcher, P., Frith, C. D., Friston, K. J., Frackowiak, R. S. J. \& Grasby, P. M. (1995). Dopaminergic modulation of cognitive in the anterior cingulate cortex in schizophrenia. Nature 378, 180-182.

Ellis, H. C., Thomas, R. L. \& Rodriguez, I. A. (1984). Emotional mood states and memory: elaborative encoding, semantic processing, and cognitive effort. Journal of Experimental Psychology: Learning, Memory and Cognition 10, 470-482.

Ellis, H. C., Thomas, R. L., McFarland, A. D. \& Lane, J. W. (1985). Emotional mood states and retrieval in episodic memory. Journal of Experimental Psychology: Learning, Memory and Cognition 11, 363-370.

Fetz, E. E. (1993). Cortical mechanisms controlling limb movement. Current Opinion in Neurobiology 3, 932-939.

Friston, K. J., Frith, C. D., Liddle, P. F., Dolan, R. J., Lammertsma, A. A. \& Frackowiak, R. S. (1990). The relationship between global and local changes in PET scans. Journal of Cerebral Blood Flow and Metabolism 10, 458-466.

Friston, K. J., Frith, C. D., Liddle, P. F. \& Frackowiak, R. S. (1991a). Plastic transformation of PET images. Journal of Computer Assisted Tomography 15, 634-639.

Friston, K. J., Frith, C. D., Liddle, P. F. \& Frackowiak, R. S. $(1991 b)$. Comparing functional (PET) images: the assessment of significant change. Journal of Cerebral Blood Flow and Metabolism 11, 690-699.

Frith, C. D., Friston, K., Liddle, P. F. \& Frackowiak, R. S. (1991a). Willed action and the prefrontal cortex in man: a study with PET. Proceedings of the Royal Society of London B 244, 241-246.

Frith, C. D., Friston, K. J., Liddle, P. F. \& Frackowiak, R. S. $(1991 b)$. A PET study of word finding. Neuropsychologia. 29 1137-1148.

George, M. S., Ketter, T. A., Parekh, P. I., Horwitz, B., Herscovitch, P. \& Post, R. M. (1995). Brain activity during transient sadness and happiness in healthy women. American Journal of Psychiatry 152, 341-351.

Gerrards-Hesse, A., Spies, K. \& Hesse, F. W. (1994). Experimental induction of emotional states and their effectiveness: a review. British Journal of Psychology 85, 55-78.

Goodwin, G. M., Austin, M. P., Dougall, N., Ross, M., Murray, C., O'Carroll, R. E., Moffoot, A., Prentice, N. \& Ebmeier, K. P. (1993). State changes in brain activity shown by the uptake of
${ }^{99 \mathrm{~m}}$ Tc-exametazime with single photon emission tomography in major depression before and after treatment. Journal of Affective Disorders 29, 243-253.

Jones, A. K. P., Brown, W. D., Friston, K. J., Qi, L. Y. \& Frackowiak, R. S. J. (1991). Cortical and subcortical localisation of response to pain in man using positron emission tomography. Proceedings of the Royal Society of London B 244, 39-44.

Kaada, B. R., Pribram, K. H. \& Epstein, J. A. (1949). respiratory and vascular responses in monkeys from temporal pole, insula, orbital surface and cingulate gyrus. Journal of Neurophysiology 12, 347-356.

Kunishio, K. \& Haber, S. N. (1994). Primate cingulostriatal projection: limbic striatal versus sensorimotor striatal input. Journal of Comparative Neurology 350, 337-356.

Lindvall, O. \& Bjorkland, A. (1983). Dopamine- and norepinephrine-containing neuron systems: their anatomy in the rat brain. In Chemical Neuroanatomy (ed. P. C. Emson), pp. 229-255. Raven Press: New York.

McGuire, P. K., Silbersweig, D. A. Murray, R. M., David, A. S., Frackowiak, R. S. J. \& Frith, C. D. (1996). Functional anatomy of inner speech and auditory verbal imagery. Psychological Medicine 26, 29-38.

Mayberg, H. S., Starkstein, S. E., Sadzot, B., Preziosi, T., Andrezejewski, P. L., Dannals, R. F., Wagner, H. N., Jr. \& Robinson, R. G. (1990). Selective hypometabolism in the inferior frontal lobe in depressed patients with Parkinson's disease. Annals of Neurology 28, 57-64.

Natale, M. \& Boylan, R. (1980). The effect of Velten's moodinduction procedure on hand and head-down posture. Motivation and Emotion 4, 323-333.

Neafsey, E. J., Hurley Gius, K. M. \& Arvanitis, D. (1986). The topographical organization of neurons in the rat medial frontal, insular and olfactory cortex projecting to the solitary nucleus, olfactory bulb, periaqueductal gray and superior colliculus. Brain Research 377, 561-570.

Pardo, J. V., Pardo, P. J., Janer, K. W. \& Raichle, M. E. (1990). The anterior cingulate cortex mediates processing selection in the Stroop attentional conflict paradigm. Proceedings of the National Academy of Sciences USA 87, 256-259.

Pardo., J. V., Pardo, P. J. \& Raichle, M. E. (1993). Neural correlates of self-induced dysphoria. American Journal of Psychiatry 150, 713-719.

Petersen, S. E., Fox, P. T., Posner, M. I., Mintun, M. \& Raichle, M. E. (1989). Positron Emission Tomographic studies of the processing of single words. Journal of Cognitive Neuroscience 1, 153-170.

Polivy, J. \& Doyle, C. (1980). Laboratory induction of mood states through the reading of self-referent mood statements: affective changes or demand characteristics? Journal of Abnormal Psychology 89, 286-290

Radenhausen, R. A. \& Anker, J. M. (1988). Effects of depressed mood induction on reasoning performance. Perceptual and Motor Skills 66, 855-860.

Raichle, M. E., Fiez, J. A., Videen, T. O., Macleod, A. M., Pardo, J. V., Fox, P. T. \& Petersen, S. E. (1994). Practice-related changes in human brain functional anatomy during nonmotor learning. Cerebral Cortex 4, 8-26.

Rauch, S. L., Jenike, M. A., Alpert, N. M., Baer, L., Breiter, H. C., Savage, C. R. \& Fischman, A. J. (1994). Regional cerebral blood flow measured during symptom provocation in obsessivecompulsive disorder using oxygen 15-labeled carbon dioxide and positron emission tomography. Archives of General Psychiatry 51, $62-70$.

Rauch, S. L., Savage, C. R. Alpert, N. M., Miguel, E. C., Baer, L., Breiter, H. C., Fischman, A. J. Manzo, P. A., Moretti, C. \& Jenike, M. A., (1995). A positron emission tomographic study of simple phobic symptom provocation. Archives of General Psychiatry 52, 333-339.

Ring, H. A., Bench, C. J., Trimble, M. R., Brooks, D. J., Frackowiak, R. S. \& Dolan, R. J. (1994). Depression in Parkinson's disease. A positron emission study. British Journal of Psychiatry 165, 333-339. 
Riskind, J. H. \& Rholes, W. S. (1985). The Velten Mood Induction Procedure and cognitive manipulation: our response to Clark (1985). Behaviour Research and Therapy 23, 671-673.

Robb, R. A. \& Hanson, A. (1990). A software system for interactive and quantitive analysis of biomedical images. In $3 D$ Imaging in Medicine: Algorithms, Systems, Applications (ed. K. H. Hohne, H. Fuchs and S. Pizer), pp 333-361. Springer Verlag: London

Rolls, E. T., Hornak, J., Wade, D. \& McGrath, J. (1994). Emotion-related learning in patients with social and emotional changes associated with frontal lobe damage. Journal of Neurology Neurosurgery and Psychiatry 57, 1518-1524.

Rosen, S. D., Paulesu, E., Frith, C. D., Frackowiak, R. S., Davies, G. J., Jones, T. \& Camici, P. G. (1994). Central nervous pathways mediating angina pectoris. Lancet 344, 147-150.

Ross, E. D. \& Stewart, R. M. (1981). Akinetic mutism from hypothalamic damage: Sucessful treatment with dopamine agonists. Neurology 31, 1435-1439.

Silbersweig, D. A., Stern, E., Frith, C. D., Cahill, C., Schnorr, L., Grootoonk, S., Spinks, T., Clark, J., Frackowiak, R. \& Jones, T. (1993). Detection of thirty-second cognitive activations in single subjects with positron emission tomography: a new low-dose $\mathrm{H}_{2}\left({ }^{15}\right) \mathrm{O}$ regional cerebral blood flow three-dimensional imaging technique. Journal of Cerebral Blood Flow and Metabolism 13, 617-629.

Spinks, T. J., Jones, T., Bailey, D. L., Townsend, D. W., Grootoonk, S., Bloomfield, P. M., Gilardi, M. C., Casey, M. E., Sipe, B. \& Reed, J. (1992). Physical performance of a positron tomograph for brain imaging with retractable septa. Physics and Medical Biology 37, 1637-1655.

Sutherland, G., Newman, B. \& Rachman, S. (1982). Experimental investigations of the relations between mood and intrusive, unwanted cognitions. British Journal of Medical Psychology 55, $127-138$.
Talairach, J. \& Tournoux, P. (1988). Co-planar Stereotaxic Atlas of the Human Brain. New York: Thieme Medical Publishers Inc.

Teasdale, J. D. \& Fogarty, S. J. (1979). Differential effects of induced mood on retrieval of pleasant and unpleasant events from episodic memory. Journal of Abnormal Psychology 88, 248-257.

Teasdale, J. D. \& Taylor, R. (1981). Induced mood and accessibility of memories: An effect of mood state or inductive procedure? British Journal of Clinical Psychology 20, 39-48.

Teasdale, J. D. \& Russell, M. L. (1983). Differential effects of induced mood on the recall of positive, negative and neutral words. British Journal of Clinical Psychology 22, 163-171.

Thorpe, S. J., Rolls, E. T. \& Maddison, S. (1983). The orbitofrontal cortex: neuronal activity in the behaving monkey. Experimental Brain Research 49, 93-115.

Velten, E. (1968). A laboratory task for induction of mood states. Behaviour Research and Therapy 6, 473-482.

Warburton, E., Wise, R. J. S., Price, C. J., Weiller, C., Hadar, U., Ramsey, S. \& Frackowiak, R. S. J. (1995). Noun and verb retrieval by normal subjects: Studies with PET. Brain 119, 159-157.

Watson, D., Clark, L. A. \& Tellegen, A. (1988). Development and validation of brief measures of positive and negative affect: the PANAS scales. Journal of Personality and Social Psychology 54, 1063-1070.

Weingartner, H., Cohen, R., Murphy, D. L., Martello, J. \& Gerdt, C. (1981). Cognitive processes in depression. Archives of General Psychiatry 38, 42-47.

Wise, R., Hadar, U., Howard, D. \& Patterson, K. (1991). Language activation studies with positron emission tomography. Ciba Foundation Symposium 163, 218-228.

Woods, R. P., Mazziotta, J. C. \& Cherry, S. R. (1993). MRI-PET registration with automated algorithm. Journal of Computer Assisted Tomography 17, 536-546. 